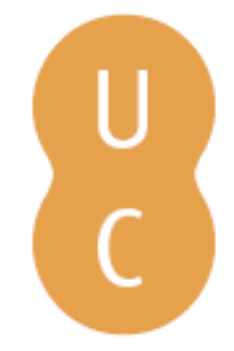

\title{
pommalina
}

\section{Museus e núcleos museológicos: factor de valorização do Touring cultural da região centro: as aldeias históricas}

Autor(es): $\quad$ Gonçalves, António Costa; Moreira, Fernando João

Publicado por: Imprensa da Universidade de Coimbra

URL

persistente: URI:http://hdl.handle.net/10316.2/30762

DOI: $\quad$ DOI:http://dx.doi.org/10.14195/978-989-26-0244-8_11

Accessed : $\quad$ 26-Apr-2023 10:08:14

A navegação consulta e descarregamento dos títulos inseridos nas Bibliotecas Digitais UC Digitalis, UC Pombalina e UC Impactum, pressupõem a aceitação plena e sem reservas dos Termos e Condições de Uso destas Bibliotecas Digitais, disponíveis em https://digitalis.uc.pt/pt-pt/termos.

Conforme exposto nos referidos Termos e Condições de Uso, o descarregamento de títulos de acesso restrito requer uma licença válida de autorização devendo o utilizador aceder ao(s) documento(s) a partir de um endereço de IP da instituição detentora da supramencionada licença.

Ao utilizador é apenas permitido o descarregamento para uso pessoal, pelo que o emprego do(s) título(s) descarregado(s) para outro fim, designadamente comercial, carece de autorização do respetivo autor ou editor da obra.

Na medida em que todas as obras da UC Digitalis se encontram protegidas pelo Código do Direito de Autor e Direitos Conexos e demais legislação aplicável, toda a cópia, parcial ou total, deste documento, nos casos em que é legalmente admitida, deverá conter ou fazer-se acompanhar por este aviso.

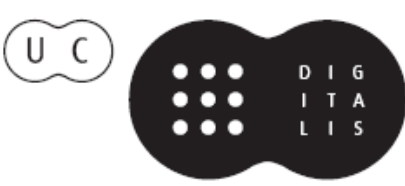




\section{TRUNFOS DE UMA}

\section{EOGRAFIA ACIVA}

\section{DESENVOLVIMENTO LOCAL,}

AMBIENTE,

ORDENAMENTO

E TECNOLOGIA

Norberto Santos

Lúcio Cunha

COORDENAÇÃO 
António Costa Gonçalves, Fernando João Moreira

ESHTE

\section{MUSEUS E NÚCLEOS MUSEOLÓGICOS: FACTOR DE VALORIZAÇÃO DO TOURING CULTURAL DA REGIÃO CENTRO - AS ALDEIAS HISTÓRICAS}

\section{NOTA INTRODUTÓRIA}

A consulta de um Dicionário da Língua Portuguesa relativamente ao vocábulo «paisagem» remete para o seguinte significado: porção de território que se abrange num lanço de olhos ${ }^{1}$.

Para além desta tradução comum, conceptualmente aponta para uma maior complexidade pela matriz sensorial que tem subjacente. A «paisagem» pode ser interpretada e descrita oralmente, através da escrita, pela pintura e composição musical. Na perspectiva geográfica, a que se nos afigura como mais favorável/próxima, estão implícitas as variáveis espaço e tempo. A maioria das definiçóes baseia-se no arranjo do espaço e consequente análise estruturada das transformaçóes operadas (Ilídio do Amaral: 2001; 76).

O período subsequente à II Guerra Mundial induziu transformaçóes no conhecimento geográfico que se traduziram, sobretudo nos últimos 25 anos, por uma «Nova» Geografia Cultural. Foram desenvolvidas várias abordagens ao conceito de «paisagem» resultando desta tendência um revivalismo de pendor humanista. Pode afirmar-se que a "paisagem» é na actualidade um poderoso instrumento de análise cultural (Sarmento: 2004; 36). No patamar da metodologia para o estudo da "paisagem» são analisados/compilados, pelos "Geógrafos Culturais», os contributos da literatura, cinema, música, moda e publicidade como forma de aferir o posicionamento dos grupos face às diferentes "paisagens». Esta praxis decorre das duas definiçóes de cultura concorrentes e, complementares que marcaram o século passado: uma destacando o ideal intelectual e estético da cultura, outra assumindo a cultura como uma forma de vida.

$\mathrm{O}$ acesso à cultura, potenciado pelo desenvolvimento socioeconómico, generalizou-se no quadro da globalização dando origem aos conceitos "consumos culturais» e «indústria do património». Tradicionalmente o património é definido como a afirmação da memória colectiva, de uma comunidade, traduzida em expressóes identitárias. Actualmente o marketing assume, neste conceito, grande protagonismo transformando valores em bens de consumo, sendo a História, cuidadosamente seleccionada, legitimadora deste processo. (Sarmento: 2004; 91). O conceito de património compreende na sua essência duas

\footnotetext{
Porto.

${ }^{1}$ Dicionário da Língua Portuguesa (1984), Dicionários Editora, 7a Edição revista e ampliada, Porto Editora,
} 
tipologias: o património natural e o cultural onde se individualizam as componentes erudita e popular. No património material, com uma estética e dimensão aceites, os processos de identificação, preservação e posterior fruição estão facilitados. Já a dimensão imaterial onde figuram as memórias, os costumes e o saber popular, requer uma maior agilidade na sua leitura e posterior utilização em favor da engenharia do produto turístico (Umbelino: 2004; 23).

As últimas décadas foram marcadas por uma crescente nostalgia e (re)descoberta dos espaços rurais onde os recursos passaram a ser entendidos, numa actualidade pós-produtivista, de outra forma. Recursos ligados à arquitectura da produção (moinhos, palheiros e lagares) estáo a ser explorados e utilizados por novos actores que potenciam usos alternativos do espaço rural transformando-o num novo espaço de consumo. Assim, pode justificar-se o papel decisivo que a «indústria do património» tem imprimido à construção e renovação de lugares. A expansão de locais e, sítios que reivindicam ser representaçôes do passado é notável tendo sido apelidada de "eclosão do património - heritage boom» (Hewison, 1987; Urry, 1992; Walsh, 1992 citados por Sarmento: 2004; 89).

\section{TOURING CULTURAL E PAISAGÍsTICO}

O Plano Estratégico Nacional do Turismo (PENT) seleccionou 10 produtos considerando a sua quota de mercado, potencial competitivo e de crescimento. O Touring Cultural e Paisagístico é um dos produtos incluído neste Plano que pretende nortear até 2015 o reforço e desenvolvimento da oferta turística nacional. Relativamente aos mercados, o sector do Touring pode ser definido ${ }^{2}$ :

Touring genérico - Tours, rotas ou circuitos de conteúdo abrangente e diversificado. O tour, rota ou circuito constituem a essência dos produtos. Representa cerca de $90 \%$ das viagens de Touring.

Touring temático - Tours, rotas ou circuitos focalizados num determinado tema, constituindo a motivação da deslocação / experienciação. Representa aproximadamente $10 \%$ do total das viagens de Touring.

Considerando ainda o tipo de transporte individualizam-se duas modalidades: o Touring independente onde a viagem é realizada com recurso a viatura própria ou fly \& drive e o Touring em grupo utilizando transporte colectivo. O Touring gera anualmente 44 milhóes de viagens internacionais na Europa de uma ou mais noites de duração com uma taxa de crescimento médio anual de 5 a $7 \%^{3}$. Quanto aos principais mercados emissores, a Itália e França lideram o ranking das viagens onde o Touring é a principal motivação ${ }^{4}$. O visitante/turista que se desloca na perspectiva do Touring privilegia, visitas a atractivos de interesse, cidades, conhecimento de paisagens e visitas a museus e espectáculos.

\footnotetext{
${ }^{2}$ Touring Cultural e Paisagístico (2006), «PDF» in http://www.turismodeportugal.pt

${ }^{3}$ Touring Cultural e Paisagístico (2006), «PDF» in http://www.turismodeportugal.pt

${ }^{4}$ Idem
} 
Relativamente à capacidade competitiva de Portugal neste segmento convém destacar o acervo constituído por catorze recursos monumentais/culturais e naturais, classificados pela UNESCO como património da humanidade. Face à dimensão territorial de Portugal pode considerar-se uma densidade patrimonial muito satisfatória. Numa segunda linha podem ainda compor a paleta da oferta turística nacional, entre outros, os sítios arqueológicos, áreas de paisagem protegida, monumentos de interesse arquitectónico/histórico, a arquitectura religiosa e as Aldeias Históricas. Sobre o público-alvo do Touring Cultural e Paisagístico consignado no PENT estão definidas duas prioridades: «prioridade 1» turistas europeus em viagem independente ou viagem organizada (package) e "prioridade 2» - turistas estrangeiros em Portugal e turistas portugueses. O PENT estabelece ainda quatro mercados prioritários hierarquizados pela proximidade: Espanha, França, Reino Unido e Itália. Numa perspectiva territorial de desenvolvimento do Touring Cultural e Paisagístico, a Região Centro é incluída numa "1a Prioridade» conjuntamente com o Porto e Norte, Lisboa e Alentejo. Nas linhas de actuação conducentes ao desenvolvimento da oferta destacam-se o reforço das Rotas existentes (Aldeias Históricas, Aldeias de Xisto e Praias Fluviais) e a criaçáo de itinerários de Touring que incluam a visita a locais de interesse natural (Parque Natural do Tejo Internacional e Serra da Estrela) e as cidades de média dimensão (Aveiro, Castelo Branco, Coimbra, Guarda e Viseu).

\section{As AldeIAS HistóricAs de PORTUGAL}

É na Região Centro que se desenvolve um dos contrastes mais vigorosos da terra portuguesa (Serra da Estrela - $1993 \mathrm{~m}$ ) coincidindo com os Territórios de Viriato e dos seus lendários guerreiros e, posteriormente, da Milícia Templária com um papel determinante na organização e fixação das fronteiras que iriam dar origem ao Condado Portucalense.

A Secretaria de Propaganda Nacional do Estado Novo, liderada por António Ferro, atribuiu em 1939 o Galo de Prata à Aldeia de Monsanto ficando ligada, até à actualidade, ao título de "Aldeia mais Portuguesa de Portugal». Esta iniciativa estava enquadrada num amplo quadro de Comemoraçóes do duplo Centenário da Nacionalidade (a fundação, em 1143, e a restauração, em 1640) que tinham como corolário a realização da Exposição do Mundo Português em 1940.

Com o lançamento do «Programa de Recuperação de Aldeias Históricas de Portugal» em 1994, antecedendo também a realização da Exposição Universal "Expo 98", evidenciou-se mais uma vez a vontade de reafirmar a identidade nacional (Dias: 1986; 40):

O Atlântico atraíra sempre com a sua magia um certo fundo sonhador e vago das populaçóes costeiras, enquanto as do interior se agarravam fortemente à solidez do solo conquistado.

Estava por esta via, e com as duas iniciativas desenvolvidas nos anos 90, assegurada a memória futura de dois traços fundamentais da história e cultura portuguesa.

O referido Programa foi concebido e desenvolvido pelo Ministério do Planeamento e Administração do Território, Secretaria de Estado do Planeamento e Desenvolvimento Regional, Direcção-Geral do Desenvolvimento Regional e pela então designada Comissão 
de Coordenação da Região Centro 5 . A estas Aldeias são reconhecidos atributos simbólicos do Portugal «ancestral», dando corpo a uma imagem forte que sabiamente apropriada pelo Turismo, constitui um factor de inovação na tradição e consolidação do território.

Onze Aldeias Históricas, com a excepção de Castelo Mendo dado não possuir Posto de Turismo, registaram em 2008 a presença de $355104^{6}$ visitantes/turistas. Almeida foi a mais visitada (75173), seguindo-se Sortelha (58993) e Castelo Rodrigo (45034). Convém sublinhar que os dados apurados, dizem apenas respeito aos visitantes/turistas que se dirigem aos Postos de Turismo constituindo assim, uma representação por defeito da realidade.

\section{MUSEOLOGIA COMO FACTOR DIFERENCIADOR - BELMONTE}

Um programa museológico compreende um conjunto de dimensôes podendo destacar-se: preservação, investigação, educação, inovação, experimentação e proactividade. $\mathrm{O}$ Museu ao utilizar o património como um suporte de conhecimento deve ser um lugar de reflexão crítica. Para avaliar a relevância de um Museu, não se deve perguntar que colecçóes tem, mas sim o que faz com esse acervo.

No denominador comum aos Museus e Turismo podem identificar-se: prazer / lazer / sonho, acolhimento / comunicação, público(s) / cultura, avaliação / marketing e uma gestão financeira eficaz.

Num quadro de renovação da paisagem cultural da Região Centro, onde o «Programa de Recuperação de Aldeias Históricas de Portugal» teve um protagonismo indiscutível, pode destacar-se a emergência de um novo acervo museológico que passou a valorizar a sua oferta turística. As unidades museológicas e os museus para além de serem equipamentos turísticos estruturantes são um lugar de cultura por excelência. Aplicando o conceito de cultura à presente realidade, será indissociável a dimensão baseada nos comportamentos, acçóes e imagens associadas a cada paisagem como resultado da apropriaçáo territorial. Uma valorizaçáo sustentada da paisagem cultural assenta em primeira instância na mobilização das comunidades locais. A reabilitação dos edifícios, arranjos dos espaços exteriores e substituição do mobiliário urbano devolvem uma dignidade adormecida e apelam a um sentimento de identidade fortemente arreigado, reforçado com a vinda dos visitantes e turistas. A reabilitação do património não deverá assentar na tentação de o petrificar na sua história e no passado nostálgico, mas sim numa refuncionalização que permita o estabelecimento de um fio de continuidade. Neste contexto, a afirmação de uma identidade deverá estar associada naturalmente a uma perspectiva dinâmica: fabrica-se quotidianamente, por um lado pela especificidade territorial, humana, histórica e geográfica, e por outro pelo presente que pode ser compreendido apenas como a projecção do futuro. Assim, uma associação das unidades museológicas e museus à actividade turística pode ser considerada como uma parceria de valor acrescentado:

- O Turismo, pela sua especificidade, apela a um processo de consumo de experiências, devendo incluir-se, obviamente, a visita de museus.

\footnotetext{
${ }^{5}$ Os núcleos seleccionados inicialmente foram: Almeida, Castelo Mendo, Castelo Novo, Castelo Rodrigo, Idanha-a-Velha, Linhares da Beira, Marialva, Monsanto, Piódão e Sortelha. Actualmente Belmonte e Trancoso estão também inseridos neste Programa.

${ }^{6}$ Fluxo de visitantes/turistas das Aldeias Históricas em 2008, (CCDRC).
} 
- O que os museus podem oferecer ao turismo é a sua produção: património cultural transformado em produtos culturais turísticos.

- O Turismo tem, geralmente, a tendência de maximizar o número de visitantes a um qualquer segmento da oferta, enquanto os Museus, preocupados com o «bem-estar» dos seus recursos, limitam o acesso aos mesmos - princípio de equilíbrio (sustentabilidade).

- Os Museus são uma parte interessada no desenvolvimento sustentável do Turismo Cultural, tendo um papel crucial na preservação e promoção do Património.

No global das 12 Aldeias Históricas foram criados 15 núcleos museológicos e museus. Belmonte, tendo desenvolvido uma forte aposta na museologia, criou 6 unidades $^{7}$. Destas, cinco $^{8}$ estão organizadas num circuito, com a possibilidade de marcaçáo de visitas guiadas e uma bilhética muito versátil em modalidades destinadas a jovens dos 13 aos 18 anos, portadores do Cartão Jovem, reformados e residentes no Concelho:

\section{IGREJA DE SÃO TIAGO - CENTRO INTERPRETATIVO DE SÁO TIAGO}

Trata-se de um Núcleo Museológico que cruza a dimensão religiosa cristá, com a família de referência de Belmonte, os Cabrais. Do ponto de vista museológico é um pólo cujo acervo é constituído pelo monumento em si (arquitectura e obras de adorno), bem como pelo património tumular aí depositado. Mais do que um Museu estamos perante um monumento visitável cuja dimensão museográfica é incipiente. Como Centro Interpretativo, a quantidade e qualidade da informação prestada é insuficiente.

\section{Museu JudAICO DE BELMONTE/CENTRO DE ESTUDOS JUDAICOS}

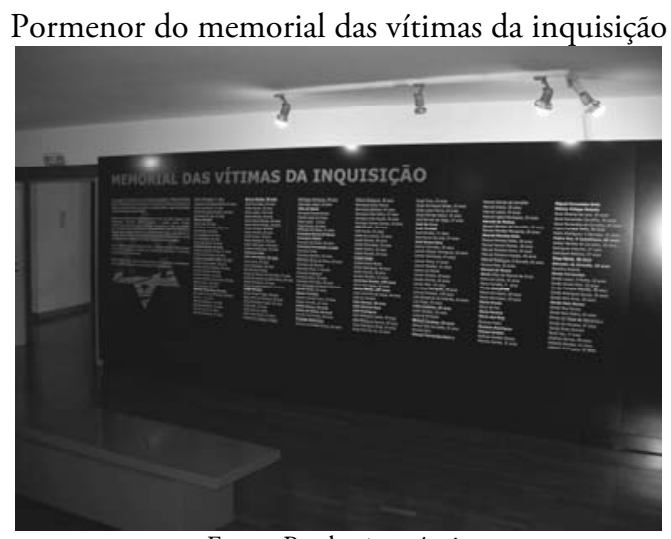

Fonte: Produção própria

\footnotetext{
7 Igreja de São Tiago - Centro Interpretativo de São Tiago, Museu Judaico de Belmonte/Centro de Estudos Judaicos, Ecomuseu do Zêzere, Museu do Azeite, Centro Interpretativo de Belmonte - À Descoberta do Novo Mundo e Villa Romana da Fórnea.

${ }^{8}$ Igreja de São Tiago - Centro Interpretativo de São Tiago, Museu Judaico de Belmonte/Centro de Estudos Judaicos, Ecomuseu do Zêzere, Museu do Azeite e Centro Interpretativo de Belmonte - À Descoberta do Novo Mundo.
} 
Focaliza-se na dimensão transcendental, ao mesmo tempo que explica a fixação dos cristãos novos nesta localidade, cruzando-se, desta forma, com o processo histórico de estruturação da localidade. Contextualiza-se numa filosofia museológica tradicional, embora servida por uma museografia bastante cuidada e sóbria. É o pólo museológico mais visitado de Belmonte, algo que remete, em termos de atractividade, para a importância da temática em detrimento da forma como a mesma é tratada na óptica da museografia.

\section{ECOMUSEU DO ZÊZERE}

Instalado na tulha dos Cabrais, o Ecomuseu do Zêzere transporta-nos para a dimensão ambiental e para a problemática da sustentabilidade. Embora se denomine de Ecomuseu, estamos perante uma estrutura museológica que náo coincide exactamente com as propostas de Rivière e Varine ${ }^{9}$ "... o ecomuseu deverá ser um espelho, onde uma população se contempla, reconhecendo-se e reconstruindo-se...», deverá ser composto pelo museu do tempo e pelo museu do espaço, os quais, em conjunto, revelarão o ajuste das populaçóes ao seu suporte natural, ao longo do complexo espaço-temporal. Estrutura-se através de uma museografia atractiva e moderna.

\section{MUSEU DO AZEITE}

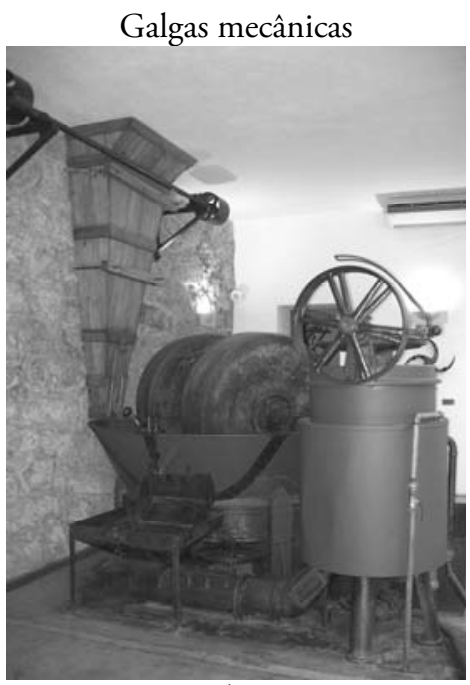

Fonte: Produção própria

Enquadrado na temática do trabalho e das actividades económicas o Museu do Azeite, como muitos dos seus congéneres, está instalado em antigas infra-estruturas de produção. Quer pela temática do trabalho, quer pelas opçóes museográficas, trata-se do Núcleo Museológico de Belmonte que mais se aproxima da chamada «Nova Museologia». Permite

\footnotetext{
${ }^{9}$ http://www.ecomusee-creusotmontceau.fr/rubrique.php3?id_rubrique=39 (consultado em 10 de Junho de 2009)
} 
dar conta de todo o processo produtivo do azeite e detém uma informação completa e atractiva em suporte audiovisual. No final do percurso, o visitante é convidado a interagir fisicamente com a temática e com o acervo museológico através de várias provas de azeite. Sem dúvida, um excelente (novo) museu.

\section{CENTRO INTERPRETATIVO DE BELMONTE - À DESCOBERTA DO NOVO MUNDO}

Um Museu na sua mais pura essência, que, partindo de um passado marcado pela projecção externa de Belmonte e do País, nos transporta para as interrogaçóes futuras associadas a um mundo crescentemente relacional e global. Trata-se de uma instituição museológica que surpreende o visitante pela amplitude da temática, mas, sobretudo, pelo arrojo e modernidade das soluçóes museográficas encontradas, na linha do museu espectáculo e do museu de envolvimento. Uma pérola museológica, em qualquer parte do mundo.

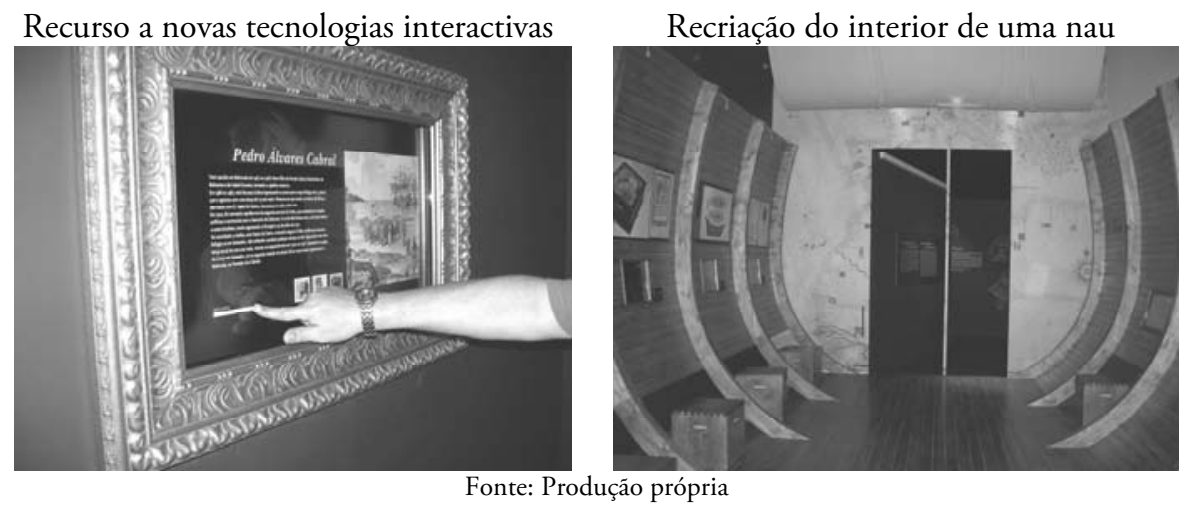

Pelo exposto pode inferir-se que a Vila de Belmonte, integrada no «Programa de Recuperação de Aldeias Históricas de Portugal», tem vindo a reforçar os seus recursos turísticos com base numa oferta museológica criteriosamente ajustada à sua identidade. A mais recente aquisição neste domínio - Centro Interpretativo de Belmonte - À Descoberta do Novo Mundo - constitui um indiscutível factor de diferenciação que poderá garantir per si a desejada valorização e polarização.

O carácter diferenciador dos recursos é ainda responsável por imprimir uma maior longevidade aos produtos turísticos a que dáo origem. Deste modo, o reforço da vertente cultural da oferta turística da Regiáo Centro é um imperativo que apela a uma constante inovação, à criaçáo de novos itinerários temáticos e a novas formas de promoção e divulgação.

\section{REFERÊNCIAS BIBLIOGRÁFICAS}

Amaral, I. 2001, "Acerca de "Paisagem»: Apontamentos para um debate» in Finisterra, Volume XXXVI, No 72, Centro de Estudos Geográficos, Lisboa.

Bartlet, T. 2008, «Rural Tourism Development in Europe» in International Forum on Rural Tourism - China 2006, Final Report, World Tourism Organization, Madrid. 
Centro de Estudos de Turismo (CESTUR) da Escola Superior de Hotelaria e Turismo do Estoril 2007, $A$ Caracterização do Turismo Interno em Portugal, Estoril.

Comissão de Coordenação da Regiāo Centro (CCRC) 2002, Aldeias Históricas de Portugal - Um Património com Futuro, Coimbra.

Comissão de Coordenação e Desenvolvimento Regional do Centro (CCDRC) 2009, Fluxo de visitantes/turistas das Aldeias Históricas em 2008, Coimbra.

Dias, J. 1986, O essencial sobre os elementos fundamentais da cultura portuguesa, Imprensa Nacional Casa da Moeda, Lisboa.

Dicionário da Língua Portuguesa 1984, Dicionários Editora, $7^{\text {a }}$ Edição revista e ampliada, Porto Editora, Porto.

Diry, J. P. 2004, Les espaces ruraux, Armand Colin, $2^{\mathrm{e}}$ Édition, Paris.

Gonçalves, A. C. 2006, "Inovação e tradição no Turismo Rural - O Programa de recuperação das Aldeias Históricas» in Actas do "Congresso Turismo Cultural, Territórios e Identidades», Escola Superior de Educação, IPL, Leiria.

Moreira, F. J. 2008, O Turismo e os Museus nas Estratégias e nas Práticas de Desenvolvimento Territorial, Dissertação apresentada para obtenção do Grau de Doutor em Museologia, no Curso de Doutoramento em Museologia, conferido pela Universidade Lusófona de Humanidade e Tecnologias, policopiado, Lisboa.

Sarmento, J. C. V. 2004, Representaçāo, Imaginaçāo e Espaço Virtual: Geografias de Paisagens Turísticas em West Cork e nos Açores, Textos Universitários de Ciências Sociais e Humanas, Fundação Calouste Gulbenkian, Fundação para a Ciência e a Tecnologia, Lisboa.

Turismo de Portugal, IP 2008, O Turismo em 2007, Lisboa.

Umbelino, J. 2004, "Turismo e Património. Algumas Ideias para Reflexão» in Revista Turismo \& Desenvolvimento, Volume 1, No 1, Associação de Gestão e Planeamento em Turismo da Universidade de Aveiro, Editorial Notícias, Lisboa.

\section{FONTES ELECTRÓNICAS}

Rivière, G. H. ; Varine, H 1971, Neuvième Conférence du Conseil International des Musées disponível em: http://www.ecomuseecreusotmontceau.fr/rubrique.php3?id_rubrique=39 (consultado em 10 de Junho de 2009).

Turismo de Portugal IP 2006, Touring Cultural e Paisagistico disponível em: http://www.turismodeportugal.pt/ (consultado em 10 de Junho de 2009). 